http://jmscr.igmpublication.org/home/ ISSN (e)-2347-176x ISSN (p) 2455-0450 crossref DOI: https://dx.doi.org/10.18535/jmscr/v9i10.18

\title{
Numerical spleen peritonitis on a case and literature review at the Centre Hospitalier Régional Amissa BONGO de Franceville Gabon ("CHRABF")
}

\author{
Authors \\ Ngakani Offobo S., Owono JP, Ondo N'dong F \\ General Surgery Department, Amissa Bongo Regional Hospital of Franceville
}

\section{Introduction}

Supernumerary spleens are rare in the general population. The unusual nature of this location poses difficult diagnostic problems. This observation reports two accessory spleens discovered intraoperatively during a laparotomy indicated for generalized peritonitis.

Keywords: Splenectomy - Splenectomy Peritonitis - Supernumerary spleen.

\section{Observation}

This is a 12-year-old boy with no specific history admitted for diffuse abdominal pain and cessation of materials in a feverish context for eight days. On examination there is fever $40{ }^{\circ} \mathrm{C}$, general asthenia, conjunctivalpallor. The abdomen is tense (wood belly)

It evokes acute peritonitis. The count notes a hyperleukocytosis 18000 white blood cells and a hypochromic microcytic anemia $5 \mathrm{~g} / \mathrm{dl}$. Ultrasound revealed abundant peritoneal effusion. Renal and hepatic functions are normal. We proceed to first resuscitation measures, hydro-electrolytic filling, a blood transfusion iso group B positive, antibiotic triage. Laparotomy reveals a purulent effusion of $1100 \mathrm{cc}$, mesenteric lymph nodes, a retro caecal perforated appendicitis and two supernumerary spleens (one on the gastroepiploic ligament and another on the splenic hilum).

Resection of the last two; conventional appendectomy, lavage, drainage. The suites are simple after a stay in intensive care. This diagnosis was confirmed by a microscopic study (histology), showing a lesional architecture similar to that of a normal spleen.

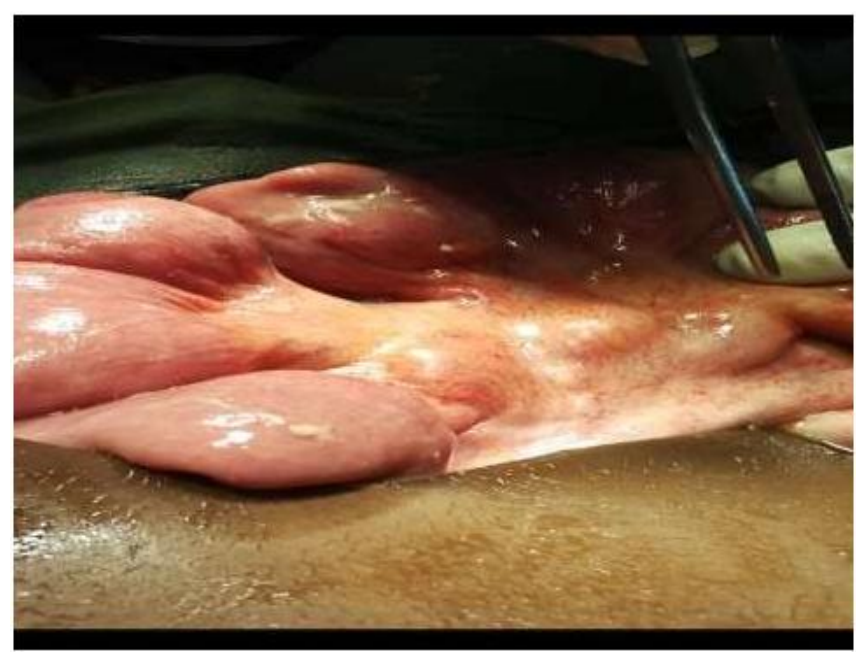

Fig. 1 Mesenteric Ganglia 


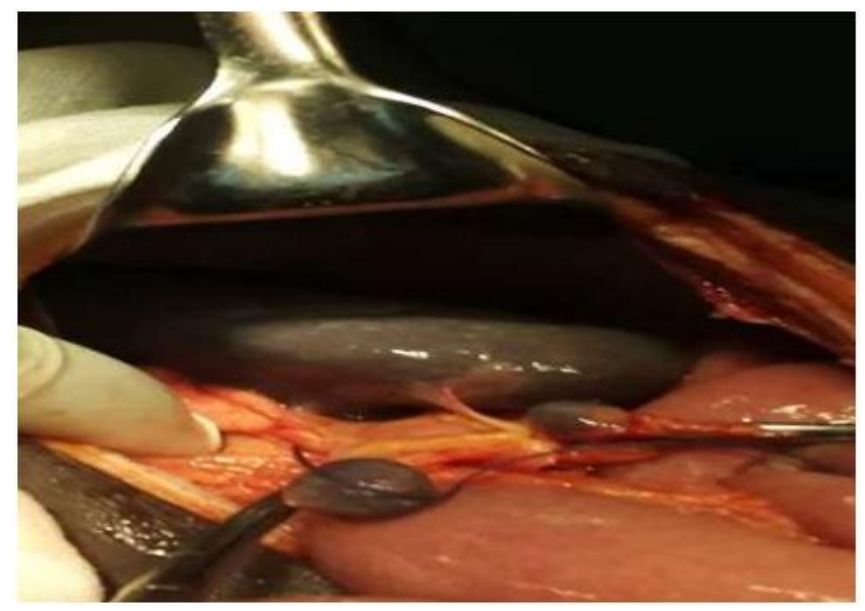

Fig. 2 supernumerary spleen

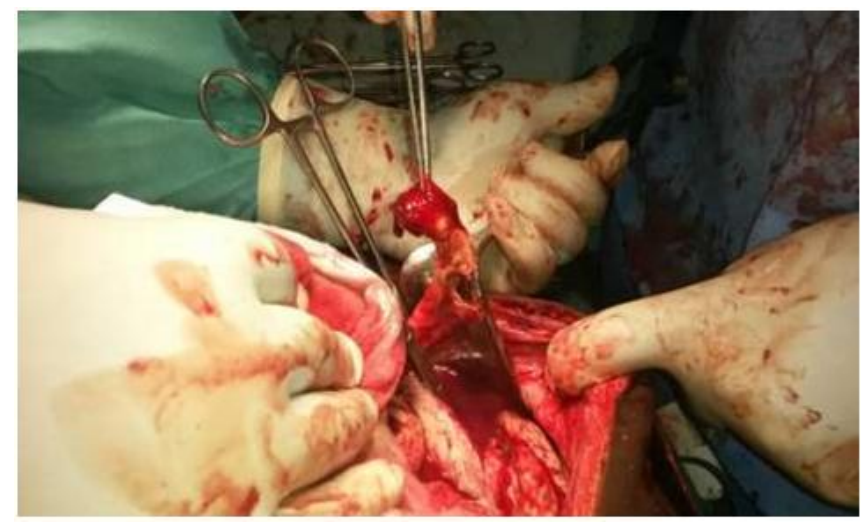

Fig. 3 Appendicis Perforated

\section{Discussion}

Supernumerary or accessory rats are found in $10 \%$ of the general population ${ }^{(1)}$. They result from the non-convergence of the primitive mesenchymal islets. Their migration can take place along the dorsal mesogaster, or along its root. The accessory spleens are thus most often located at the level of the hilum of the normal spleen.

However, they can also be located along the splenic artery, at the tail of the pancreas, in the gastrosplenic or orenal splenic ligament, in the mesentery, and sometimes even in the pelvis or scrotum $^{(2)}$. Intrapancreatic localization is dueto the proximity of the embryonic drafts of the spleen and tail of the pancreas inthe posterior mesogaster (fifth week of intrauterine life ${ }^{(6)}$. These splenic islets are usually vascularized by branches of the splenic artery. If they are large, their venous drainage may be performed by an accessory splenic vein $^{(3)}$.

The accessory spleen differs from a splenic nodule, which is an abdominal or thoracic graft of splenic parenchyma secondary to spleen trauma. The nodules are then multiple, disseminated at the peritoneal or thoracic level. They have nocapsule, no hilum, and have a dystrophic parenchyma. Their vascularization comes from the peritoneum or pleura.

Two cases of intrapancreatic accessory spleen have been reported in imagingto our knowledge in the literature ${ }^{(4,7)}$. Our observation found two spleens in intraoperative peritonitis in front of a generalized peritonitis. The discovery is most often fortuitous with a normal clinical and biological assessment. Ultrasonography revealed an isosechoic lesion in the pancreas at the limit of visibility. The MRI examination has the advantage of showing a pancreatic nodule with the same intensity as the spleen on the SPT'I and T2

The main differential diagnoses are: non-secretory endocrine tumors, angiomatous tumors and hypervascular metastases (kidney cancer in particular). Pancreatic sarcomas are hypervascular tumors in CT, but often the distinction is obvious due to heterogeneity and loco-reoional invasion. If doubt persists after CT and MRI scans, a scintigraphy with marked red blood cells (Tc99 m) may help to correct the diagnosis by demonstrating the presence of splenic sequestration in the lesion if it is large enough ${ }^{(5,8)}$. The puncture biopsy does not seem to be of much interest in the assessment because of thedifficulties posed by the approach, and because of the splenic nature of the tissue to be removed.

In conclusion, the discovery of a well-limited hypervascular homogeneous nodule of the tail of the pancreas, which presents the same signal as the spleen on MRI, should suggest the diagnosis of intrapancreatic accessory spleen. Scintigraphy with marked red blood cells, showing the splenic nature of the lesion, may avoid the need for surgery to confirm the diagnosis.

\section{Conclusion}

We report a case of two supernumerary spleens found intraoperatively in front of a generalized 
peritonitis. This unusual localization can easily be confused with tumors. The diagnosis can be evoked by a scintigraphy with marked red blood cells and confirmed by post-operative histology.

\section{References}

1. Halpert B, Gyorkey F. Lesions observed in accessory spleens of 311 patients. Am J Clin Pathol 1959; 32 : 165-8.

2. Wick MR, RiTe CC. Paratesticular accessory spleen. Mayo Clin Proc 1981; $56: 455-6$.

3. Clark RE, Korobkin M, Palubinskas AJ. Angiography of accessory spleen. Radiology 1972;1O2 :, 41-4.

4. Hayward 1. Mindelzun RE, JeTIrey RB. Intrapancreatic accessory spleen mimicking pancreatic mass on CT. J Comput Assist Tomogr '1 992 ; 16 : 984-5.

5. Freeman JL, Zatar S, Jafri H. CT oT congenital and acquired abnormalities of the spleen. Radiographics 1993; 13 : 597-6 10.

6. Witold J, Rudowski MD. Accessory spleens: clinical signifiance with particular reference to the recurrence of idiopathic thrombocytopenic purpura. World J Surg 1985; 9:422-30.

7. Harris G, Kase D, Bradnock H, Mckinley lvl. Accessory spleen causing a mass in the tail of the pancreas: MR imaging findings. AJÆ 1994; 163: 1120-1.

8. Sezeur A, De Labriole-Vaylet CL, Douay L, Goujard F, Wioland M, Desmarquet J. Intérêt de la scintigraphie peropératoire pour reperer les rates accessoires. La Presse Medicale 1990; $19: 1$ 100-2. 